\title{
Analisis Penyerapan Tenaga Kerja (Studi Pada UKM Kerupuk Sanjai di Kabupaten Lima Puluh Kota)
}

\author{
Analysis of Labor Absorption \\ (Study in Kerupuk Sanjai Small and Medium Enterprises \\ in Kabupaten Lima Puluh Kota)
}

\author{
Nelvia Iryani ${ }^{1}$, Syaiful Anwar ${ }^{2}$ \\ ${ }^{1}$ Fakultas Ekonomi Universitas Andalas Padang, nelvia.iryani@ gmail.com \\ ${ }^{2}$ Fakultas Ekonomi Universitas Andalas Padang, ipung.pyk@gmail.com
}

\begin{abstract}
Abstrak
Tenaga kerja merupakan aset yang sangat penting dalam kegiatan ekonomi, akan tetapi seringkali jumlah tenaga kerja melebihi kapasitas lapangan kerja yang tersedia, sehingga sangat diperlukan untuk menganalisis faktor-faktor yang mempengaruhi penyerapan tenaga kerja. Penelitian ini bertujuan untuk mengestimasi hubungan antara variabel upah, modal, nilai produksi terhadap penyerapan tenaga kerja pada Usaha Kecil dan Menengah (UKM) Kerupuk Sanjai di Kabupaten Limapuluh Kota. Jenis penelitian ini adalah field research (riset lapangan) dan menggunakan data primer yang dikumpulkan melalui kuesioner kepada 100 UKM kerupuk sanjai di Kabupaten Limapuluh Kota. Alat analisis yang digunakan adalah analisis regresi linear berganda dengan metode OLS (Ordinary Least Square) dan pengolahan data menggunakan software SPSS VR.21. Hasil penelitian menunjukkan bahwa ketiga variabel bebas dalam penelitian ini berpengaruh signifikan terhadap variabel terikat (penyerapan tenaga kerja). Modal kerja merupakan variabel yang paling besar pengaruhnya dalam penyerapan tenaga kerja pada UKM kerupuk sanjai di Kabupaten Limapuluh Kota.
\end{abstract}

Kata Kunci: modal, nilai produksi, tenaga kerja, UKM, upah

\section{Abstract}

Labor is a very important asset in economic activities, but often the number of workers exceeds the available employment capacity, so it is very necessary to analyze the factors that affect employment. This study aims to estimate the relationship between wage, capital, production value to the amount of employment in Kerupuk Sanjai Small and Medium Enterprises (SMEs) in Kabupaten Limapuluh Kota This type of research is field research and use questioner to 100 respondens. The analytical tool used is multiple linear regression analysis with OLS (Ordinary Least Square) method and data processing using SPSS VR.21 software. The results of the study show that all independent variabels has a significant effect on labor absorption in Kerupuk Sanjai SMEs in Kabupaten Limapuluh Kota. capital is the variable that has the most influence in the absorption of labor in the Kerupuk Sanjai Small and Medium Enterprises (SMEs) in Kabupaten Limapuluh Kota.

Keywords: labor, wage, capital, production value, Small and Medium Enterprises

\section{Pendahuluan}

Indonesia merupakan salah satu negara dengan jumlah penduduk terbesar di dunia. Pertumbuhan penduduk yang tinggi menimbulkan peningkatan angkatan kerja yang akan memasuki pasar tenaga kerja. Badan Pusat Statistik mencatat jumlah angkatan kerja Indonesia pada Februari 2017 sebanyak 131,55 juta orang. Jumlah tersebut naik 6,11 juta dibanding tahun 2016 dan naik 3,03\% atau 3,88 juta dibandingkan Februari 2016 [1]. Peningkatan jumlah tenaga kerja menyebabkan bertambahnya penawaran tenaga kerja., Sementara itu di satu sisi, aktifitas ekonomi tidak mampu menyerap semua tenaga kerja tersebut. Hal ini dikarenakan rata-rata tingkat pendidikan angkatan kerja di Indonesia adalah rendah. 
Tingkat pendidikan akan berkorelasi dengan keterampilan dan produktifitas. Kondisi ini menjadikan tenaga kerja Indonesia sulit untuk bekerja di sektor formal yang mensyaratkan tingkat pendidikan dan keahlian, sehingga terjadi apa yang dikenal dengan pengangguran. Salah satu alternatif untuk mengatasi permasalahan tersebut yaitu dengan memberdayakan sektor informal serta sektor ekonomi tradisional. Sektor informal dengan karakteristik jumlah unit usaha yang banyak dalam skala kecil, teknologi sederhana dan padat karya, tingkat pendidikan dan keterampilan yang rendah dapat menyerap tenaga kerja yang tidak bisa memasuki sektor formal. Kementrian Koperasi dan UMKM menyebutkan tahun 2011 lebih dari 55,2 juta unit UKM mampu meyerap sekitar 101, 7 juta orang. Angka tersebut meningkat menjadi 57,8 juta unit UKM dengan jumlah tenaga kerja yang terserap mencapai 114 juta orang pada tahun 2012. Dengan penyerapan tenaga kerja yang cukup meningkat tersebut maka UKM juga mampu meningkatkan pendapatan masyarakat. Dengan kata lain UKM memiliki peran yang cukup strategis dalam memerangi kemiskinan dan pengangguran.

UKM adalah satu sektor informal yang keberadaannya memberikan nilai positif dalam perekonomian. Sektor ini dapat berkembang dengan mudah karena tidak membutuhkan modal yang terlalu besar, teknologi relatif sederhana, dan bahan baku relatif mudah didapatkan. Sektor ini memberikan kemungkinan kepada tenaga kerja yang berlebih yang dapat bekerja dengan tingkat pendidikan dan keahlian rendah. Salah satu UKM yang berpotensi untuk dikelola atau dikembangkan adalah UKM yang memproduksi serta menjual aneka kerupuk Sanjai. UKM yang mengolah singkong menjadi aneka keripik ini telah ada sejak lama dan berkembang di Propinsi Sumatera Barat, salah satunya di Kabupaten Limapuluh Kota. Olahan aneka keripik sanjai sering dijadikan oleh-oleh bagi para wisatawan yang berkunjung ke Propinsi Sumatera Barat.

Sebagai salah satu bagian dari usaha kecil, UKM kerupuk sanjai menjadi salah satu sektor yang mampu menciptakan kesempatan kerja di Kabupaten Limapuluh Kota, sehingga dapat meningkatkan pendapatan masyarakat. Perkembangan UKM kerupuk sanjai di Kabupaten Limapuluh Kota merupakan industri rumah tangga yang tumbuh dan berkembang secara turun temurun, dengan proses produksi serta penggunaan alat yang masih sederhana, sehingga industri ini lebih berkarakter labor intensive. Pertambahan penduduk di pedesaan yang relatif besar akan mempersempit luas lahan pertanian, sehingga kesempatan kerja di bidang pertanian menjadi terbatas. UKM diperlukan untuk mengimbangi kesempatan kerja dan angkatan kerja yang ada. Terserapnya penduduk bekerja disebabkan oleh adanya permintaan akan tenaga kerja. Oleh sebab itu penyerapan tenaga kerja dapat dikatakan sebagai permintaan tenaga kerja [4]. Upah dibagi menjadi tiga macam [8], yaitu: (1) upah pokok yaitu upah yang diberikan pada karyawan, yang dibedakan atas upah per jam, per hari, per minggu, per bulan; (2) upah lembur yaitu upah yang diberikan kepada karyawan yang bekerja melebihi jam kerja yang telah ditetapkan perusahaan; (3) tunjangan, yaitu uang yang diterima karyawan secara menyeluruh karena adanya keuntungan dari erusahaan pada akhir tahun neraca.

Berdasarkan latar belakang yang telah diuraikan, maka rumusan masalah dalam penelitian ini, antara lain: (a) bagaimana pengaruh upah, modal dan nilai produksi terhadap penyerapan tenaga kerja pada UKM yang memproduksi aneka kerupuk sanjai di Kabupaten Limapuluh Kota ? (b) Variabel manakah yang paling dominan pengaruhnya terhadap penyerapan tenaga kerja pada UKM yang memproduksi aneka kerupuk sanjai di Kabupaten Limapuluh Kota ? Adapun tujuan dari dilakukannya penelitian ini adalah:

1. Untuk menganalisa pengaruh upah, modal, dan nilai produksi terhadap penyerapan tenaga kerja pada UKM yang memproduksi aneka kerupuk sanjai di Kabupaten Limapuluh Kota

2. Untuk menganalisa variabel mana yang paling dominan pengaruhnya terhadap penyerapan tenaga kerja pada UKM yang memproduksi aneka kerupuk sanjai di Kabupaten Limapuluh Kota.

\section{Metode Penelitian}

Penelitian ini merupakan penelitian field research (riset lapangan), yaitu melakukan penelitian di lapangan untuk memperoleh data atau informasi secara langsung dengan mendatangi responden pengusaha kerupuk sanjai di kabupaten Limapuluh Kota. Dalam penelitian ini pendekatan yang digunakan adalah pendekatan kuantitatif. Teknik pengambilan sampel dilakukan 
secara random. Dalam penelitian ini, karena jumlah populasinya tidak diketahui, maka penentuan jumlah sampel menggunakan teori Isac Michael:

$$
n=\frac{\left(Z_{\alpha / 2}\right)^{2} \cdot p \cdot q}{e^{2}}
$$

Dimana:

$\mathrm{n}=$ sampel

$\mathrm{p}=$ proporsi sample

$\mathrm{q}=1-\mathrm{p}$

$\mathrm{Z}=$ tingkat ke[ercayaan

$\mathrm{e}=$ margin error

$\alpha=1$ - tingkat signifikansi

Sehingga pengumpulan data menggunakan instrumen penelitian melalui wawancara dan pengisian kuesioner kepada 100 unit UKM kerupuk sanjai di Kabupaten Limapuluh Kota. Alat analisis yang digunakan dalam penelitian ini yaitu Regresi Linear Berganda dengan metode analisis Ordinary Least Square (OLS) yang meggunakan program SPSS VR 21 [3]. Berdasarkan model dan variabel dalam penelitian maka dibentuklah sebuah persamaan, yaitu :

Dimana:

$$
\mathrm{Y}=\mathrm{Ln} \beta_{0}+\beta_{1} \operatorname{Ln} \mathrm{X}_{1}+\beta_{2} \operatorname{Ln} \mathrm{X}_{2}+\beta_{3 \mathrm{Ln}} \mathrm{X}_{3}+\mathrm{Ui}
$$

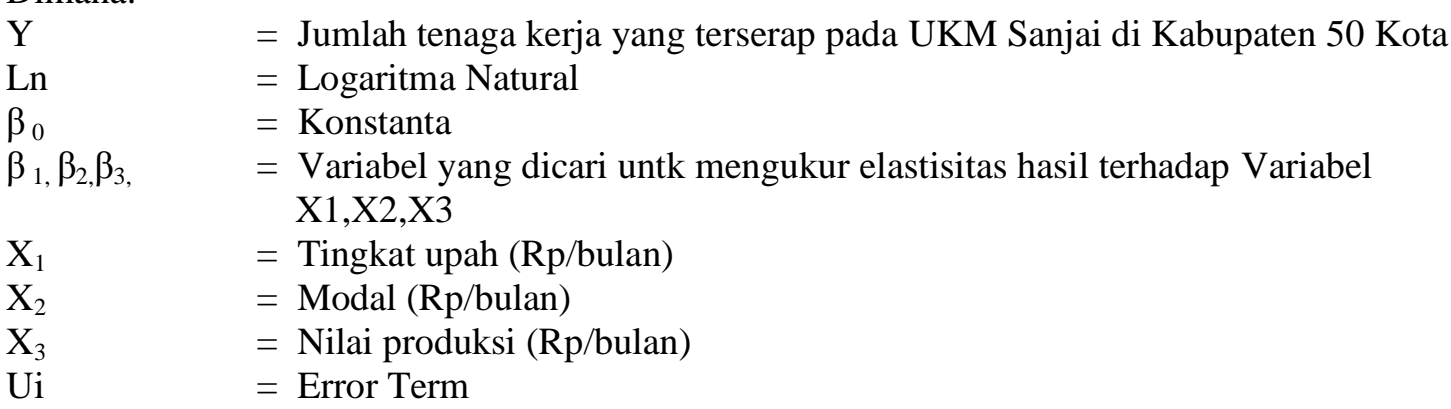

Berdasarkan teori dan penelitian terdahulu maka kerangka berpikir dalam penelitian ini dapat disederhanakan dalam bentuk kerangka konseptual seperti pada gambar berikut:

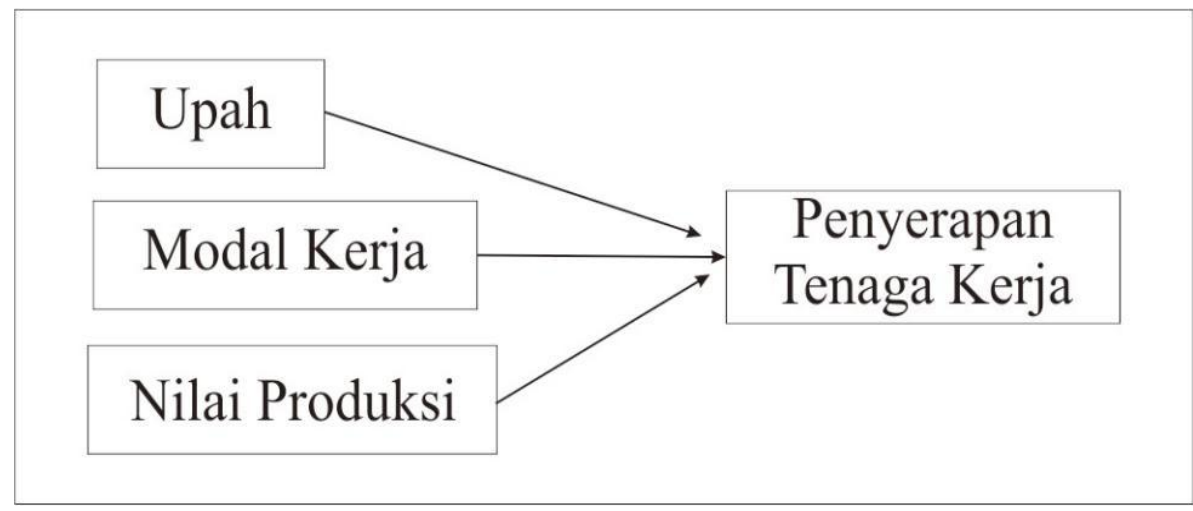

Gambar 1. Kerangka pemikiran teoritis

\section{Pengujian Regresi}

Koefisien Determinasi $\left(R^{2}\right)$

Koefisien determinasi $\left(R^{2}\right)$ pada intinya digunakan untuk mengukur seberapa jauh kemampuan variabel bebas dalam menerangkan variabel terikat. Nilai koefisien determinasi adalah $0<R^{2}<1$. Variabel independen dikatakan dapat mengambarkan perubahan pada variable dependen ditandai dengan $\mathrm{R}^{2}$ yang nilainya tinggi atau mendekati 1 , sedangkan jika variabel independen tidak dapat menggambarkan variabel dependen maka ditandai dengan $\mathrm{R}^{2}$ yang kecil/rendah atau mendekati [5]. 
Pengujian F- Statistik

Uji Statistik F dimaksudkan untuk mengetahui apakah variabel bebas secara bersama-sama mempunyai pengaruh terhadap variabel terikat. Dalam penelitian ini pengujian dilakukan dengan tingkat signifikan $95 \%(\alpha=0,05=5 \%)$. Jika $\mathrm{F}$ hit $>\mathrm{F}$ Tabel, maka $\mathrm{H}_{1}$ diterima dan $\mathrm{H}_{0}$ ditolak, berarti masing-masing variabel bebas secara bersama-sama mempunyai pengaruh yang signifikan terhadap variabel terikat, tapi jika Fhit $<\mathrm{F}$ Tabel, maka $\mathrm{H}_{1}$ ditolak dan $\mathrm{H}_{0}$ diterima, hal ini berarti masingmasing variabel bebas secara bersama-sama tidak memiliki pengaruh yang signifikan terhadap variabel terikat [2]

\section{Pengujian t-Statistik}

Uji t-Statistik sangat diperlukan dalam melakukan analisis hasil penelitian. Uji ini digunakan untuk menunjukkan apakah suatu variabel bebas secara individu mempengaruhi variabel terikat. Dalam penelitian ini menggunakan kriteria pengujian dengan tingkat signifikansi $95 \%(\alpha=0,05)$. Apabila $\mathrm{t}$ hit $>\mathrm{t}$ tabel, maka $\mathrm{H}_{1}$ diterima dan $\mathrm{H}_{0}$ ditolak, berarti variabel bebas secara parsial mempunyai pengaruh yang signifikan terhadap variabel terikat. Sedangkan, jika $t$ hit $<\mathrm{t}$ tabel, maka $\mathrm{H}_{0}$ diterima dan $\mathrm{H}_{1}$ ditolak, berarti variabel bebas secara parsial mempunyai pengaruh yang signifikan terhadap variabel terikat [2].

\section{Pengujian Asumsi Kasik Uji Normalitas}

Uji normalitas bertujuan untuk mengetahui apakah nilai residual yang distandarisasikan berdistribusi normal atau tidak. Dalam penelitian ini model yang terdistribusi haruslah normal, dikatakan normal apabila niai residual yang terstandarisasikan tersebut sebagian besar mendekati rata-rata. Metode yang digunakan untuk uji normalitas dalam penelitian ini yaitu uji KolmogorovSmirnov, dimana jika signifikansi (Sig) $>\alpha=0,05$ maka data berdistribusi normal. Dan jika signifikansi (Sig) $<\alpha=0,05$ maka data tidak berdistribusi normal[4].

\section{Uji Linearitas}

Pengujian linearitas digunakan untuk mengetahui model yang dihasilkan linear atau tidak. Penelitian ini linearitas terjadi atau tidak dapat menggunakan metode Lm. Test. Dimana suatu model dikatakan linear apabila $\mathrm{X}^{2}$ Hitung $>\mathrm{X}^{2}$ tabel dengan $\mathrm{df}=(\mathrm{n}, \mathrm{a})[6]$.

\section{Uji Heteroskedastisitas}

Uji Heteroskedastisitas bertujuan untuk melihat apakah terdapat ketidaksamaan varians dari residual satu pengamatan ke pengamatan yang lain. Dalam penelitian ini untuk mendeteksi terjadinya heteroskedastisitas pada suatu model dapat dilihat dengan metode Glejser. Menurut Suliyanto apabila terdapat variabel bebas yang signifikan terhadap nilai mutlak residualnya (sig < a) maka dalam model terdapat masalah heteroskedastositas dan sebaliknya. Untuk uji asumsi klasik dengan uji heteroskedastisitas data yang dikehendaki adalah data yang bebas heteroskedastisitas [6] Uji Autokorelasi

Dalam penelitian ini, untuk mendeteksi apakah terjadi autokorelasi atau tidak adalah dengan metode Breusch-Godfrey (B-G test) dimana jika $\mathrm{X}^{2}$ hitung $<\mathrm{X}^{2}$ tabel maka model tidak mengandung masalah autokorelasi dan sebaliknya. Untuk mencari nilai $\mathrm{X}^{2}$ hitung diperoleh dari (n$\mathrm{p})^{*} \mathrm{R}^{2}$ dan $\mathrm{X}^{2}$ tabel didapatkaan dari df $(\mathrm{p}, \alpha)$. Dalam uji asumsi klasik dengan menggunakan uji autokorelasi data yang dikehendaki adalah data yang bebas autokorelasi [6].

\section{Uji Multikolinearitas}

Pengujian terhadap multikolinieritas dilakukan untuk mengetahui apakah antar variabel bebas itu saling berkolerasi. Model regresi yang baik seharusnya tidak terjadi korelasi diantara variabel bebas. Menurut Suliyanto untuk mendeteksi model regresi apakah data bebas multikolinearitas atau tidak dilakukan dengan pengujian TOL ( ToleranceI ) dan VIF ( Variance Inflation Factor ) dari masing-masing variabel bebas terhadap variabel terikatnya. Jika nilai TOL tidak kurang dari 0,1 dan VIF nya tidak boleh lebih dari 10 maka dapat dikatakan model tidak mengandung multikolinearitas [6]. 


\section{Hasil dan Pembahasan}

Koefisien Determinasi $\left(R^{2}\right)$

Koefisien determinasi ( $\mathrm{R}$ Square) bertujuan untuk mengetahui seberapa besar hubungan variabel bebas terhadap variabel terikat yang dinyatakan dalam persen (Gujarati, 2003). Berdasarkan hasil pengujian regresi dengan menggunakan SPSS.VR 21, dapat dilihat pada tabel 1 bahwa nilai R Square diperoleh sebesar 0,540 artinya pada derajat kepercayaan $95 \%$ sebesar $54 \%$ penyerapan tenaga kerja pada UKM kerupuk sanjai dipengaruhi oleh upah, modal dan nilai produksi. Sedangkan sisanya sebesar $46 \%$ dipengaruhi oleh variabel atau faktor yang lain selain yang diteliti.

Tabel 1. Output SPSS Model Summary

Hodel Summary

\begin{tabular}{|l|l|r|r|r|}
\hline Model & $\mathrm{R}$ & $\mathrm{R}$ Square & \multicolumn{1}{c|}{$\begin{array}{c}\text { Adjusted R } \\
\text { Square }\end{array}$} & $\begin{array}{c}\text { Std. Error of } \\
\text { the Estimate }\end{array}$ \\
\hline 1 & $.735^{a}$ & 540 & .526 & .58242 \\
\hline
\end{tabular}

a. Predictors: (Constant), Modal (Rp), Upah (Rp), Nilai Produksi (Rp)

Sumber : Data diolah menggunakan SPSS. VR 21

\section{Uji Signifikansi Simultan (Uji F)}

Uji $\mathrm{F}$ digunakan untuk menguji keberartian semua variabel bebas secara bersama-sama terhadap variabel terikat. Berdasarkan hasil penelitian pada tabel 2 didapatkan bahwa nilai $\mathrm{F}$ hitung sebesar 37,608 dengan tingkat signifikansi sebesar 0,000. Sehingga dapat diinterpretasikan bahwa upah, modal, dan nilai produksi secara bersama-sama mempengaruhi penyerapan tenaga kerja pada UKM kerupuk sanjai di Kabupaten Limapuluh Kota.

Tabel 2. Output SPSS Uji F-tes ANOVA ${ }^{\text {b }}$

\begin{tabular}{|ll|r|r|r|r|r|}
\hline Model & & \multicolumn{1}{c|}{$\begin{array}{c}\text { Sum of } \\
\text { Squares }\end{array}$} & df & Mean Square & F & Sig. \\
\hline 1 & Regression & 38,271 & 3 & 12,757 & 37,608 &, $000^{a}$ \\
& Residual & 32,565 & 96 &, 339 & & \\
& Total & 70,836 & 99 & & & \\
\hline
\end{tabular}

a. Predictors: (Constant), Modal (Rp), Upah (Rp), Nilai Produksi (Rp)

b. Dependent Variable: Jumlah Tenaga Kerja (Orang)

Sumber : Data diolah menggunakan SPSS. VR 21

\section{Uji Signifikansi Parsial (Uji t)}

Uji t dilakukan dengan membandingkan nilai t-hitung seluruh variabel bebas (independen) dengan nilai t-tabel. Uji t bertujuan untuk melihat hubungan atau pengaruh anatar variabel independen secara indovidual terhadap variabel dependen [3]. Berikut hasil pengujian pengaruh variabel secara parsial seperti pada tabel 3 :

Tabel 3. Output SPSS Uji T-tes

Coefficients $^{a}$

\begin{tabular}{|ll|r|r|r|r|r|}
\hline \multirow{2}{*}{ Model } & \multicolumn{2}{|c|}{ Unstandardized Coefficients } & $\begin{array}{c}\text { Standardized } \\
\text { Coefficients }\end{array}$ & & \\
\cline { 2 - 5 } & \multicolumn{1}{|c|}{$\mathrm{B}$} & \multicolumn{1}{|c|}{ Std. Error } & \multicolumn{1}{c|}{ Beta } & \multicolumn{1}{c|}{ Sig. } \\
\hline 1 & (Constant) & $-6,959$ &, 912 & & $-7,633$ &, 000 \\
& Upah (Rp) &, 138 &, 024 &, 398 & 5,663 &, 000 \\
& Nilai Produksi (Rp) &, 170 &, 069 &, 226 & 2,487 &, 015 \\
& Modal (Rp) &, 279 &, 067 &, 381 & 4,178 &, 000 \\
\hline
\end{tabular}

a. Dependent Variable: Jumlah Tenaga Kerja (Orang)

Sumber : Data diolah menggunakan SPSS. VR 21 
Untuk variabel upah, berdasarkan persamaan regresi diperoleh koefisien upah sebesar 0,138 dengan nilai signifikan 0,000 pada tingkat kepercayaan 95\% $(\alpha=0,05)$, sehingga dapat diinterpretasikan bahwa secara parsial terdapat pengaruh positif dan signifikan upah terhadap penyerapan tenaga kerja pada UKM kerupuk sanjai di Kabupaten Limapupuh Kota. Hal ini berarti jika upah meningkat maka penyerapan tenaga kerja juga mengalami peningkatan.

Selanjutnya, hasil regresi yang dilakukan menunjukkan bahwa modal memiliki pengaruh positif dan signifikan terhadap penyerapan tenaga kerja pada UKM kerupuk sanjai di Kabupaten Limapuluh Kota. Koefisien yang diperoleh sebesar 0,279, Hal ini berarti, apabila modal kerja meningkat maka penyerapan tenaga kerja juga akan meningkat. Nilai koefisien nilai produksi0,170 dengan tingkat signifikansi sebesar 0,015 pada derejat kepercayaan $95 \%(\alpha=0,05)$. Hal ini berarti, semakin bertambah nilai produksi maka penyerapan tenaga kerja juga akan semakin meningkat.

Hasil analisis uji asumsi klasik

\section{Uji normalitas}

Uji normalitas dimaksudkan untuk menguji apakah nilai residual yang telah distandarisasi pada model regresi terdistribusi normal atau tidak [6]. Berdasarkan uji normalitas dengan teknik Kolmogornov-Smirnov diperoleh hasil sebagai berikut:

Tabel 4. Uji Normalitas dengan Kolmogorov Smirnov

\begin{tabular}{|c|c|c|}
\hline \multicolumn{3}{|c|}{ One-Sample Kolmogorov-Smirnov Test } \\
\hline & & $\begin{array}{c}\text { Standardized } \\
\text { Residual }\end{array}$ \\
\hline $\mathrm{N}$ & & 100 \\
\hline Normal Parameters ${ }^{a \cdot b}$ & Mean & $0 \mathrm{E}-7$ \\
\hline & Std. Deviation &, 98473193 \\
\hline Most Extreme Differences & Absolute &, 058 \\
\hline & Positive & 058 \\
\hline & Negative &,- 036 \\
\hline Kolmogorov-Smirnov Z & &, 581 \\
\hline Asymp. Sig. (2-tailed) & & 888 \\
\hline
\end{tabular}

Sumber : Data diolah menggunakan SPSS. VR 21

Berdasarkan output hasil pengujian normalitas dengan menggunakan teknik KolmogornovSmirnov seperti yang disajikan pada tabel 4, terlihat bahwa nilai Asymp.sig(2-tailed)>alpha 0.05 yaitu sebesar 0.888 . Hal ini berarti bahwa nilai residual terstandarisasi dinyatakan menyebar secara normal.

\section{Uji multikolinieritas}

Uji multikolinieritas dilakukan untuk menguji apakah pada model regresi ditemukan adanya korelasi antar variabel independent. Jika dalam model regresi yang terbentuk terdapat korelasi yang tinggi atau sempurna antara variabel bebas maka model tersebut dinyatakan mengandung gejala multikolinieritas. Untuk menguji ada atau tidaknya gejala multikolinieritas dapat dilakukan dengan melihat collinerity statistic dari nilai VIF yang tidak melebihi 10. Berikut adalah hasil output yang diperoleh untuk pengujian multikolinieritas:

Tabel 5. Uji Multikolineariti dengan VIF

\begin{tabular}{|c|c|c|c|c|c|c|c|c|}
\hline \multicolumn{9}{|c|}{ Coefficients $^{\bar{a}}$} \\
\hline \multirow[b]{2}{*}{ Model } & & \multicolumn{2}{|c|}{ Unstandardized Coefficients } & \multirow{2}{*}{$\begin{array}{c}\begin{array}{c}\text { Standardized } \\
\text { Coefficients }\end{array} \\
\text { Beta } \\
\end{array}$} & \multirow[b]{2}{*}{$t$} & \multirow[b]{2}{*}{ Sig. } & \multicolumn{2}{|c|}{ Collinearity Statistics } \\
\hline & & $B$ & Std. Error & & & & Tolerance & VIF \\
\hline \multirow[t]{4}{*}{1} & (Constant) & $-6,959$ & .912 & & $-7,633$ & .000 & & \\
\hline & Upah (Rp) & 138 & .024 & .398 & 5,663 &, 000 & .972 & 1,029 \\
\hline & Nilai Produksi (Rp) & .170 & .069 & .226 & 2,487 &, 015 & .578 & 1,731 \\
\hline & Modal (Rp) & 279 & 067 & 381 & 4,178 & 000 & 576 & 1,735 \\
\hline
\end{tabular}

Sumber : Data diolah menggunakan SPSS. VR 21 
Berdasarkan output pada tabel 5 terlihat bahwa nilai nilai VIF untuk variabel upah, nilai produksi, dan modal < dari 10. Dengan demikian dapat disimpulkan bahwa dalam model regresi tidak terdapat gejala multikolinieritas [3].

\section{Uji heteroskedastisitas}

Uji heteroskedastisitas bertujuan untuk menguji apakah dalam sebuah model regresi terjadi ketidaksamaan varians atau residual dari satu pengamatan ke pengamatan yang lain. Salah satu cara untuk mendeteksi ada atau tidaknya heteroskedastisitas dalam sebuah model regresi adalah dengan melihat grafik plot antara nilai prediksi variabel dependen yaitu Zpred dengan residualnya Sresid [6]. Berikut ini merupakan scatterplot dari hasil pengujian:

\section{Scatterplot}

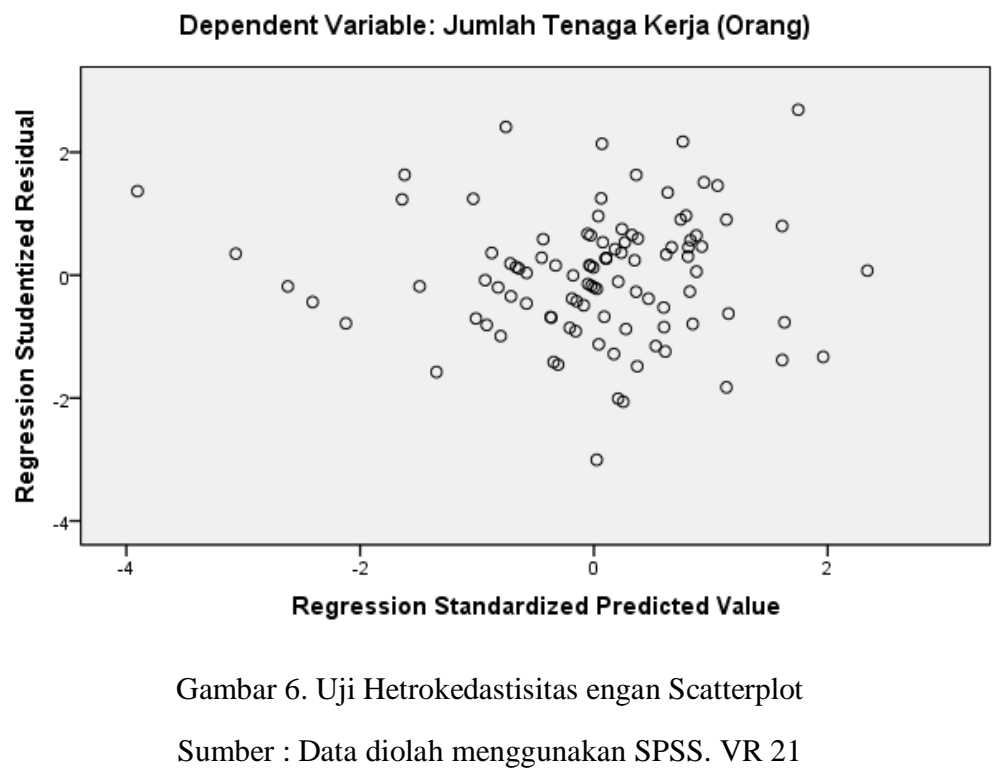

Berdasarkan tampilan output pada gamar 2 terlihat bahwa plot menyebar secara acak diatas maupun dibawah angka nol sumbu regression studentized residual. Oleh karena itu berdasarkan uji heterosedastisitas menggunakan metode analisis grafik dapat dinyatakan tidak terjadi heteroskedastisitas.

\section{Kesimpulan}

Berdasarkan hasil dan pembahasan maka dapat ditarik kesimpulan, secara bersama-sama faktor upah, nilai produksi, dan modal berpengaruh terhadap penyerapan tenaga kerja pada UKM kerupuk sanjai di Kabupaten Limapuluh Kota. Secara parsial ketiga variabel bebas (upah, nilai produksi dan modal) berpengaruh positif terhadap penyerapan tenaga kerja pada UKM kerupuk sanjai di Kabupaten LimapuluhKota, dan variabel yang paling besar pengaruhnya adalah modal

\section{Daftar Pustaka}

[1] Badan Pusat Statistik.2018. Statistik Industri Besar dan Kecil. Badan Pusat Statistik. Jakarta.

[2] Ghozali, Imam. 2013. Aplikasi Analisis Multivariat dengan Program IMB SPSS21. Semarang: Badan Penerbit Universitas Diponegoro.

[3] Gujarati, Domar. N. 2013. Dasar-dasar Ekonometrika Jilid 1. Jakarta: Erlangga.

[4] Kuncoro, Haryo, 2002, Upah Sistem Bagi Hasil dan Penyerapan Tenaga Kerja. Jurnal Ekonomi dan Bisnis Indonesia, Vol 7

[5] Santoso, Singgih. 2007. Statistik Deskriptif: Konsep dan Aplikasi dengan Microsoft Excel dan SPSS. ANDI: Yogyakarta. 
[6] Setiaji, B. 2004.Panduan Riset dengan Pendekatan Kuantitatif PPS. Universitas Muhammadiyah : Surakarta.

[7] Suliyanto. 2013. Ekonometrika Terapan : Teori dan Aplikasi dengan SPSS. Andi: Yogyakarta.

[8] Sumarsono, Sonny, 2003. Upah Minimum bagi Buruh dan Strategi Perjuangan Serikat Pekerja atau Serikat Buruh, Jurnal Analisis Sosial Vol,7, no.1 